\title{
Effect of Monascus Fermentation on Aroma Patterns of Semi-Dried Grass Carp
}

\author{
Kang Wu, Jinghui Xie, Qianqian Wang, Meijing Ling, Jianzhong Wu* \\ Department of Food Science and Engineering, Jinan University, Guangzhou, China \\ Email: 15826824041@163.com, *twjzh@jnu.com
}

How to cite this paper: $\mathrm{Wu}, \mathrm{K} ., \mathrm{Xie}, \mathrm{J} .-\mathrm{H}$., Wang, Q.-Q., Ling, M.-J. and Wu J.-Z. (2019) Effect of Monascus Fermentation on Aroma Patterns of Semi-Dried Grass Carp. Food and Nutrition Sciences, 10, 923-936. https://doi.org/10.4236/fns.2019.108066

Received: July 7, 2019

Accepted: August 10, 2019

Published: August 13, 2019

Copyright $\odot 2019$ by author(s) and Scientific Research Publishing Inc. This work is licensed under the Creative Commons Attribution International License (CC BY 4.0).

http://creativecommons.org/licenses/by/4.0/

(c) (i) Open Access

\begin{abstract}
The aim of the present study is to investigate the effects of Monascus fermentation on the aroma pattern of semi-dried grass carp. Semi-dried fish was fermented using Monascus purpureus GDMCC3.439. The volatile flavor substances present in fresh fish, semi-dry fish and Monascus fermented semi-dried fish were compared by simultaneous distillation and extraction combined with gas chromatograph-mass spectrometer (GC-MS). The results showed that alcohols, aldehydes and ketones were the main components of the flavor of the unfermented and fermented semi-dried grass crap. Monascus fermentation could significantly affect the volatile flavor substances of semi-dried grass carp. Moreover, the processing of semi-dried fish fermented by Monascus could not only effectively improve the fishy smell of fresh fish, but also make up for the defect of the pickled flavor of semi-dried fish. Eighteen of the main volatile components in semi-dried fish fermented by $\mathrm{Mo}$ nascus were identified by relative odor activity value (ROAV), as follows: 1-octene-3-ol, phenylethanol, hexanal, heptanal, nonanal, (E)-2-octenal, 3Methyl-1-butanal, benzaldehyde, (E)-2-nonenal, (E,E)-2,4-heptadienal, (E)-2Decenal, phenylacetaldehyde, (E,E)-2.4-decadienal, tetradecanal, 2,3-butanone, 2,3-octanedione, alpha-pinene, 2-pentane furan.
\end{abstract}

\section{Keywords}

Monascus, Fermentation, Semi-Dried Grass Carp, ROAV, Flavor

\section{Introduction}

Grass carp (Ctenopharyngodon idellus), one of the four largest freshwater fish in China, is very popular among consumers because of its rapid growth, high yield, and low price [1]. Grass carp is mainly freshly sold due to the high cost of storage [2]. Moreover, the production of fresh fish is greatly influenced by seasonal 
and regional weather conditions. To prevent fresh fish from deterioration, it is commonplace for the fish to be processed into salted fish. However, the traditional salted fish has high salt content and poor taste, which does not meet the dietary habits of modern people.

In recent years, a kind of low salt semi-dried fish has come into the markets. It has been welcomed by many people because of low salt content and good taste [3]. The grass carp processed into the low salt semi-dried fish has the broad market prospect. However, it suffers from having fewer flavor substances than traditional salted fish as a result of lower salt content, shorter drying time and the lack of natural inoculation and fermentation process. This problem paves the need for improvement in the flavor of fish meat. For instance, You gang et al. [4] inoculated compounded Lactobacillus on ornate threadfin bream. The results showed that a lot of carbonyl and alcohol compounds present in the flavor substances of fermented fish, which added the unique flavor of fermented fish on the basis of traditional salted fish flavor. Furthermore, Wu haiyan et al. [5] made use of Lactic acid bacteria and Staphylococcus to ferment the white cloud mountain minnows. Compared with the salted fish marinated by traditional techniques, the content of small molecules in the fermented fish meat was significantly increased, and the flavor of the final fermentation product was improved. To add on, Udomsil et al. [6] utilized Staphylococcus isolated from the traditional fish sauce as a starter culture to prepare fish sauce, which induced sauce black chocolate aroma and improved the flavor of fish sauce.

Monascus belongs to Eurotiales, Euascomycetes, Ascomycota, and Eumycophyta. It is one of the traditional fermentation moulds used by human beings and is mainly used in fermented food in some Asian countries. Monascus has been used for more than 1000 years in the production of wine, vinegar, and soy sauce in China. GDMCC3.439 Monascus purpureus is a kind of Monascus. It can produce Monascus red pigment in large quantities and has strong inhibition effect on alcohol, salinity and bacteriostasis [7].

In order to further enhance the flavor of semi-dried fish, Monascus was inoculated to ferment the semi-dried fish. The aroma-producing effect of Monascus fermentation on low salt semi-dried grass carp was analyzed. The present study attempted to provide some new ideas for the traditional salted fish technology.

\section{Materials and Methods}

\subsection{Materials and Reagents}

Grass carp was purchased from China Resources Vanguard Supermarket. Monascus purpureus GDMCC3.439 was purchased from Guangdong Culture Collectioncenter of Microbiology. $\mathrm{C}_{7}-\mathrm{C}_{30}$ normal paraffins were purchased from the American Supelco Company. Potato dextrose agar (PDA) medium was purchased from Guangdong Huankai Microbiology Co., Ltd. Soy protein isolate was purchased from Shanghai Maclean Biochemical Technology Co., Ltd. All other 
chemicals and solvents used in the study were of analytical grade.

\subsection{Main Instruments}

7890A-5975C Gas Chromatography-Mass Spectrometer was purchased from Agilent Company. Chromatographic column was HP-INNOWAX $(60 \mathrm{~m} \times 0.25$ $\mathrm{mm} \times 0.25 \mathrm{um}$ ). Simultaneous distillation and extraction (SDE) was obtained from Guangzhou Dongju Experimental Instrument Co., Ltd. Vigreux column was purchased from Guangzhou Congyuan Experimental Instrument Co., Ltd.

\subsection{Processing Craft}

\subsubsection{Preparation of Starter Cultures}

The activated Monascus were inoculated into the slope composed of PDA medium in a test tube and cultured at $30^{\circ} \mathrm{C}$ for $7-10$ days. Then $5 \mathrm{~mL}$ of sterile water was pumped into the tube, shaken for 15 minutes, and the red-brown spores were washed into the Monascus culture medium with the $6 \mathrm{~g}$ of rice powder as a carbon source, $2.5 \mathrm{~g}$ of soybean protein as nitrogen source, and $0.05 \mathrm{~g}$ of $\mathrm{MgSO}_{4}$ and $0.1 \mathrm{~g} \mathrm{KH}_{2} \mathrm{PO}_{4}$ as the mineral elements to incubate Monascus in the shaker for 5 days under $35^{\circ} \mathrm{C}$, shaking at $150 \mathrm{r} / \mathrm{min}$. after which Monascus starter cultures were prepared. The concentration of Monascus was $10^{9} \mathrm{CFU} / \mathrm{mL}$ [7].

\subsubsection{Craft of Low Salt Semi-Dried Fish}

The Scale, head, tail, fin and viscera of grass carp were removed and cut into small pieces. They were marinated at $4^{\circ} \mathrm{C}$ for 2 hours after $3 \%$ of salt $(\mathrm{W} / \mathrm{W})$ was added to them, then put into a heat pump drier, and dried at $27^{\circ} \mathrm{C}$ and $20 \%$ humidity until the moisture content of the fish was about $50 \%$. Finally, after vacuum packaging, they were unfermented group samples.

\subsubsection{Craft of Low Salt Semi-Dried Fish Fermented by Monascus}

The Scale, head, tail, fin and viscera of grass carp were removed and cut into small pieces. They were marinated at $4^{\circ} \mathrm{C}$ for 2 hours after $3 \%(\mathrm{~W} / \mathrm{W})$ of salt was added to them. Monascus starter cultures were evenly applied to ferment them, and the inoculation amount was $5 \mathrm{~mL} / 100 \mathrm{~g}$. Then, they were fermented at $30^{\circ} \mathrm{C}$ for 18 hours, and transferred to a heat pump dryer. Next, they were dried at $27^{\circ} \mathrm{C}$ and $20 \%$ humidity until the moisture content of the fish was about $50 \%$. Finally, after vacuum packaging, they were fermented group samples.

\subsection{Collection of Volatile Compounds}

$30 \mathrm{~g}$ of fish meat was placed in a $1000 \mathrm{~mL}$ round-bottom flask with $400 \mathrm{~mL}$ of purified water and the flask attached to the side of the SDE device. A $500 \mathrm{~mL}$ round-bottom flask containing $50 \mathrm{~mL}$ of dichloromethane was linked to the other side of the SDE device. The steams were cooled due to the circulation of water at $4^{\circ} \mathrm{C}$, the content of two round-bottom flasks were heated to a boil. The temperature of the dichloromethane flask was maintained by a water bath at 
$55^{\circ} \mathrm{C}$. The extraction was continued for $3 \mathrm{~h}$, the extracts were collected and refrigerated overnight with $10 \mathrm{~g}$ of anhydrous sodium sulfate. The volume of the extract was then concentrated to $3 \mathrm{~mL}$ with a Vigreux column. $600 \mathrm{uL}$ of sample concentrates were accurately absorbed into a $1.5 \mathrm{~mL}$ of sample bottle with 300 $\mathrm{uL}$ of butanol (the concentration was $400 \mathrm{ug} / \mathrm{mL}$ ) as the internal standard. The sample bottle was frozen in the refrigerator for GC-MS analysis.

\subsection{GC-MS Analysis Condition}

Chromatographic columns used HP-INNOWAX $(60 \mathrm{~mm} \times 0.25 \mathrm{~mm} \times 0.25$ um). Helium was used as the carrier gas, the gas at a flow rate of $1.0 \mathrm{~mL} / \mathrm{min}$. The column temperature was maintained at $50^{\circ} \mathrm{C}$ for $2 \mathrm{~min}$, programmed at $5^{\circ} \mathrm{C} / \mathrm{min}$ to $220^{\circ} \mathrm{C}$ and maintained for $5 \mathrm{~min}$. The mass spectrometer was operated in electron impact (EI) ionization mode with electron energy of $70 \mathrm{eV}$ and temperature at $230^{\circ} \mathrm{C}$. The four-stage bar temperature was $150^{\circ} \mathrm{C}$. Scan range was $30-550 \mathrm{~m} / \mathrm{z}$.

\subsection{Qualitative Analysis}

Unknown compounds were matched with the NIST08 library. Only compounds with mass greater than 75 were reported. Using the same heating program and taking saturated alkanes from $\mathrm{C}_{7}$ to $\mathrm{C}_{30}$ as the standard, the Retention Index (RI) of the corresponding compounds was calculated and qualitatively analyzed with the database retrieval results [8].

$$
\mathrm{RI}=100 n+100 \times \frac{t_{x}-t_{n}}{t_{n+1}-t_{n}}
$$

$t_{x}$ the retention time of the volatiles to be tested ( $\left.\min \right)$.

$t_{n}, t_{n+1}$ : the retention time of saturated alkanes containing $n$ and $n+1$ carbon atoms $(\mathrm{min})$

\subsection{Quantitative Analysis}

Butanol was used as an internal standard, and the peak area of each test substance and internal standard were compared. The concentration of the volatile substance in the sample was calculated.

$$
C=\frac{S \times 133.3 \mathrm{ug} / \mathrm{mL} \times 3 \mathrm{~mL}}{3 \mathrm{~kg}} \times 1.5
$$

$S$ : the ratio of peak area of volatile matter measured to that of internal standard butanol.

$C$ : the concentration of the volatile substance $(\mu \mathrm{g} / \mathrm{kg})$.

\subsection{Evaluation of Volatile Flavor Components by ROAV Method}

Relative odor activity value (ROAV) was used to evaluate the contribution of volatile flavor components to the flavor of Monascus fermented semi-dried fish [9] [10]. ROAV of each compound was calculated according to the following 
formula:

$$
\mathrm{ROAVi} \approx \frac{C_{i}}{C_{\text {stan }}} \times \frac{T_{\text {stan }}}{T_{i}} \times 100
$$

ROAVi: the relative odor activity value of a volatile component.

$C_{i}$ : the concentration of a volatile component $(\mathrm{ug} / \mathrm{kg})$.

$T_{i}$ : the sensory threshold of a volatile component $(\mathrm{ug} / \mathrm{kg})$.

$C_{\text {stan }}$ : the concentration of the component with maximum contribution to odors (ug/kg).

$T_{\text {stan }}$ : the sensory threshold of the component with maximum contribution to odors. (ug/kg)

\section{Results and Analysis}

\subsection{Detection Results of SDE-GC-MS}

The total ion chromatograms of the fresh fish group, unfermented semi-dried fish group and the fermented semi-dried fish group were determined by SDE-GC-MS, respectively, as shown in Figure 1, Figure 2 and Figure 3.

Specific substances were identified by searching the NIST08 spectral library and the retention index was calculated according to Equation (1). Compared with the concentration and peak area of the internal standard, the concentration of other substances was calculated by Equation (2), as shown in Table 1. The types and relative contents of volatile substances in fish meat under different processing methods were further studied, as shown in Table 2.

From Table 1, compared with the fresh fish group, the contents of hexanal, Heptanal, nonanal, (E)-2-octenal, (E)-2-nonenal, (E)-2-decenal, (E,E)-2,4-decadienal, (E,E)-2,4-heptadienal, 1-pentene-3-ol and 1-octen-3-ol significantly decreased in the fermentation group. Based on the literature analysis, these low molecular

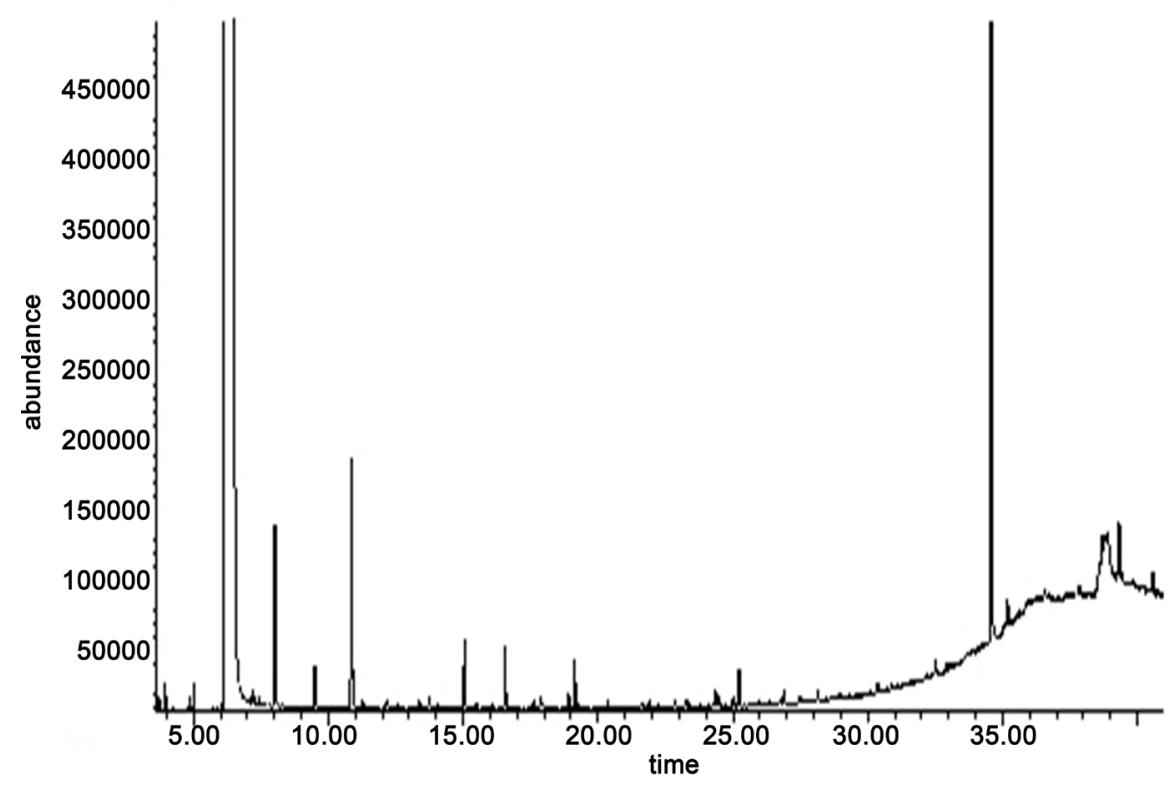

Figure 1. The total ion count (TIC) chromatogram of fresh fish sample. 


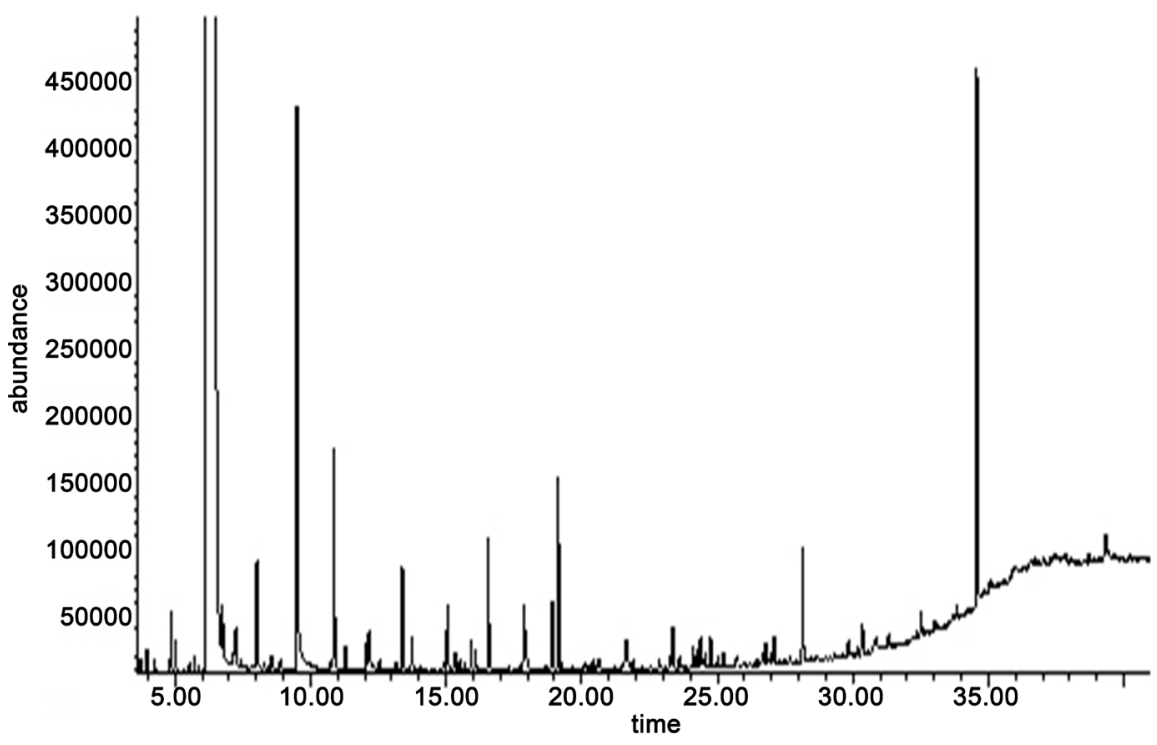

Figure 2. The total ion count (TIC) chromatogram of unfermented semi-dried fish sample.

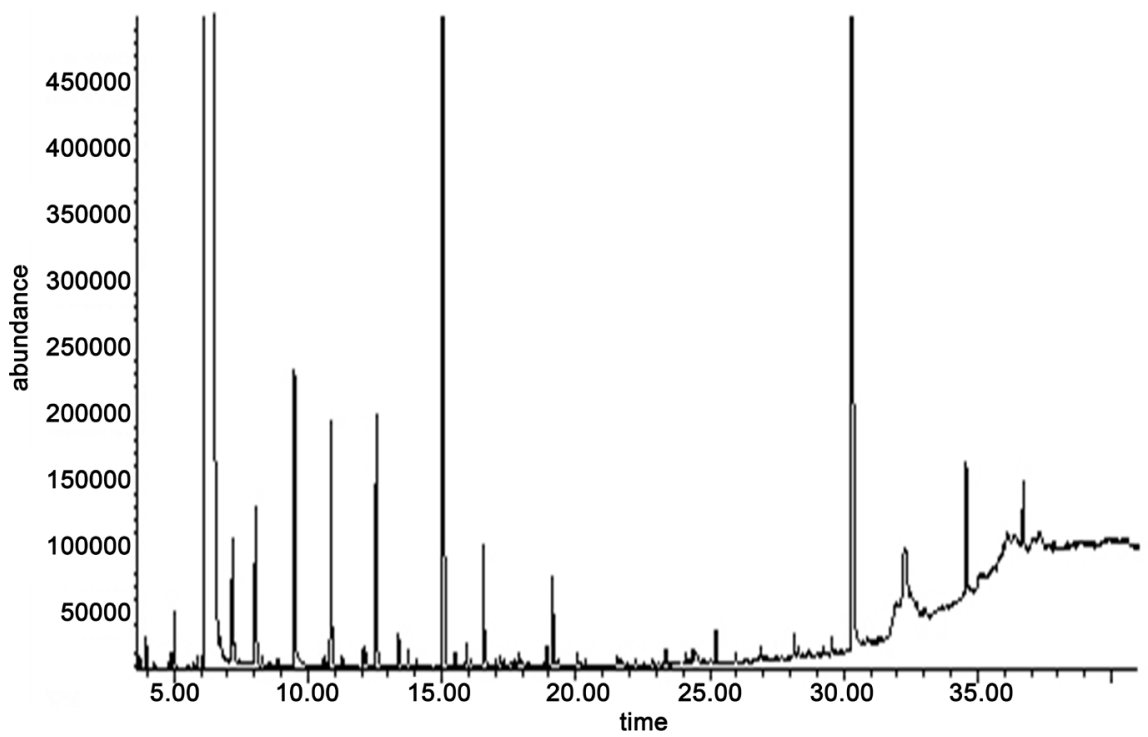

Figure 3. The total ion count (TIC) chromatogram of semi-dried fish sample fermented by Monascus.

weight aldehydes and alcohols, especially hexanal, heptaldehyde, nonanal, (E,E)2,4-decadienal, (E,E)-2,4-heptadienal were typical fishy odor-causing compounds [11] [12] [13] [14] [15]. Moreover, 1-octene-3-alcohol had mushroom aroma and earthy odor [16]. The results showed that the processing of semi-dry grass carp could effectively improve the fishy smell.

Compared with the non-fermented group, the contents of 3-methyl butanol, pentanol, hexanol, heptanol, benzaldehyde and 3-Methyl-1-butanal increased in the fermented group. It had been reported that 3-methyl butanol, 1-pentene-3alcohol, 1-octen-3-ol, pentanol, hexanol, hexanal, heptanal, benzaldehyde and 3-Methyl-1-butanal were the main flavor substances of salted fish [17] [18] [19] [20]. The results showed that the Monascus fermentation could enhance the 
Table 1. Volatile components and contents of fish meat processed in different ways.

\begin{tabular}{|c|c|c|c|c|c|}
\hline $\mathrm{RT} / \mathrm{min}$ & Element & $\begin{array}{c}\text { Fresh fish } \\
\text { group } \\
\text { (ug/kg) }\end{array}$ & $\begin{array}{l}\text { Unfermented } \\
\text { group (ug/kg) }\end{array}$ & $\begin{array}{c}\text { Fermented } \\
\text { group } \\
\text { (ug/kg) }\end{array}$ & RI \\
\hline 7.186 & 3-Methyl-3-buten-2-ol & 68.25 & - & - & 982 \\
\hline 8.294 & Propanol & - & - & 83.40 & 1038 \\
\hline 10.855 & Butanol & 1999.95 & 1999.95 & 1999.95 & 1144 \\
\hline 11.270 & 1-Penten-3-ol & 135.30 & - & 126.45 & 1160 \\
\hline 13.162 & Trans-2-Hexenal & - & 87.00 & 184.80 & 1231 \\
\hline 13.739 & Pentanol & 186.45 & - & 697.95 & 1252 \\
\hline 15.042 & 3-Methyl-2-Pentanol & - & 741.15 & 757.50 & 1300 \\
\hline 16.081 & 3-Methylbutan-1-ol & - & 1857.80 & 2124.45 & 1338 \\
\hline 16.554 & Hexanol & 2625.90 & - & 742.95 & 1356 \\
\hline 17.615 & 3-Octanol & 42.75 & - & - & 1395 \\
\hline 17.880 & (E)-2-Methylcyclopentanol & - & - & 187.20 & 1404 \\
\hline 19.138 & 1-Octen-3-ol & 3135.45 & 958.80 & 1827.30 & 1460 \\
\hline 20.245 & Fenipentol & - & 30.75 & - & 1495 \\
\hline 21.895 & Octanol & 302.70 & 3703.50 & 391.50 & 1561 \\
\hline 21.884 & Nonanol & 71.10 & 666.30 & 198.75 & 1562 \\
\hline 23.360 & (E)-2-decen-1-ol & 22.65 & - & - & 1621 \\
\hline 24.283 & 2-Butyloctan-1-ol & - & - & 44.10 & 1625 \\
\hline 24.387 & 2,2-Dimethyl-3-Octanol & - & 335.25 & - & 1664 \\
\hline 24.560 & 2-Furanmethanol & - & 125.85 & - & 1671 \\
\hline 25.829 & Ethanol, 2-(dodecyloxy) & - & - & 116.10 & 1726 \\
\hline 27.029 & 2-Hexyl-1-decanol & 6.75 & 78.75 & 81.75 & 1780 \\
\hline 25.956 & 3-Methylthiopropanol & - & - & 127.35 & 1732 \\
\hline 29.555 & Benzyl alcohol & - & - & 112.65 & 1896 \\
\hline \multirow[t]{2}{*}{30.328} & Phenylethyl alcohol & & 637.80 & 3995.40 & 1933 \\
\hline & Grand total & 8597.25 & $11,222.90$ & $13,799.55$ & \\
\hline 4.787 & Propanal & - & 131.40 & 48.45 & 791 \\
\hline 5.721 & Butanal & - & 97.20 & 32.85 & 872 \\
\hline 7.255 & Pentanal & 33.45 & 252.00 & 288.00 & 987 \\
\hline 7.256 & Butanedial & 46.05 & - & - & 994 \\
\hline 9.493 & Hexan al & 2730.45 & 2092.50 & 2263.50 & 1091 \\
\hline 12.170 & Heptanal & 1153.90 & 859.00 & 1003.50 & 1194 \\
\hline 16.081 & (Z)-2-ptenal & 6.00 & - & 63.90 & 1338 \\
\hline 16.681 & 3-Hydroxy-butanal & 6.00 & - & - & 1360 \\
\hline 17.881 & Nonanal & 2778.95 & 2046.50 & 2767.50 & 1404 \\
\hline 18.919 & (E)-2-octenal & 314.15 & 250.25 & 203.10 & 1444 \\
\hline
\end{tabular}




\section{Continued}

\begin{tabular}{|c|c|c|c|c|c|}
\hline 20.372 & 3-Methy-1-butanal & - & 502.00 & 666.00 & 1500 \\
\hline 20.465 & 2-Methylundecanal & - & 91.800 & - & 1504 \\
\hline 21.549 & Benzaldehyde & 78.45 & 64.50 & 117.00 & 1547 \\
\hline 21.641 & (E)-2-nonenal & 114.15 & - & 63.00 & 1551 \\
\hline 20.649 & (E,E)-2,4-heptadienal & 327.15 & 126.00 & 288.00 & 1511 \\
\hline 24.272 & (E)-2-decenal & 46.65 & - & 36.00 & 1659 \\
\hline 24.491 & Phenylacetaldehyde & - & 58.50 & 945.00 & 1668 \\
\hline 28.159 & $(\mathrm{E}, \mathrm{E})-2,4$-decadienal & 354.15 & 369.00 & 117.00 & 1824 \\
\hline \multirow[t]{2}{*}{34.574} & Tetradecanal & 3999.45 & 3754.95 & 3000.00 & 2148 \\
\hline & grand total & $11,988.95$ & $10,695.60$ & $11,902.80$ & \\
\hline 5.017 & Acetone & 187.20 & 241.65 & - & 814 \\
\hline 5.813 & 4-Hydroxy-2-butanone & - & - & 101.70 & 879 \\
\hline 6.067 & 2-Butanone & - & - & 130.50 & 900 \\
\hline 7.186 & 2,3-Butanedione & 90.15 & 243.60 & 886.05 & 980 \\
\hline 10.647 & (E)-3-penten-2-One & - & - & 93.75 & 1136 \\
\hline 12.078 & 2-Heptanone & 81.30 & 330.60 & 167.25 & 1191 \\
\hline 14.904 & 6-Methylheptan-2-One & - & 80.10 & - & 1235 \\
\hline 15.054 & 3-Hydroxy-2-Butanone & 261.30 & - & 3905.85 & 1300 \\
\hline 15.331 & Cyclohexanone & - & 226.35 & - & 1310 \\
\hline 15.504 & 1-Hydroxy-2-Propanone & - & 132.45 & - & 1317 \\
\hline 15.919 & 2,3-Octanedione & 1205.40 & 1233.00 & 1363.95 & 1332 \\
\hline 24.756 & 3,6-Dimethyl-4-octanone & - & 256.65 & 53.85 & 1680 \\
\hline \multirow[t]{2}{*}{27.306} & 1-Hepten-3-one & - & - & 53.10 & 1792 \\
\hline & Grand total & 1825.35 & 2744.40 & 6756.00 & \\
\hline 3.956 & 3-Methyl-1-butene & 133.35 & 151.35 & 166.20 & 600 \\
\hline 4.244 & Heptane & - & 113.55 & - & 702 \\
\hline 4.798 & 2,4-Dimethyl-heptane & 91.50 & - & - & 792 \\
\hline 4.821 & Octane & 85.05 & 384.00 & 82.95 & 796 \\
\hline 5.444 & (Z)-3-octene & - & 91.20 & - & 849 \\
\hline 5.629 & (Z)-2-octene & - & 33.60 & - & 863 \\
\hline 8.051 & Alpha-Pinene & - & - & 1799.40 & 1027 \\
\hline 8.559 & Toluene & - & 126.15 & - & 1050 \\
\hline 17.292 & 1-Ethyl-2,4-dimethylbenzene & - & 59.85 & - & 1383 \\
\hline 17.765 & 2,3,3-Trimethyloctane & - & 73.80 & - & 1400 \\
\hline 25.229 & Heptadecane & 289.05 & 124.80 & 250.65 & 1699 \\
\hline 29.324 & 2-Methyl-naphthalene & 49.65 & - & - & 1885 \\
\hline
\end{tabular}




\section{Continued}

\begin{tabular}{|c|c|c|c|c|c|}
\hline & Grand total & 648.60 & 1158.30 & 2299.20 & \\
\hline 5.848 & Ethyl acetate & - & - & 74.70 & 801 \\
\hline 6.044 & Formic acid, ethenyl ester & 37.50 & - & - & 898 \\
\hline 17.304 & $\begin{array}{l}\text { N'-Ethyl-hydrazinecarboxylic acid } \\
\text { methyl ester }\end{array}$ & - & - & 69.00 & 1383 \\
\hline 22.472 & Methoxyacetic acid, tridecyl ester & - & - & 129.60 & 1584 \\
\hline 23.291 & Oxalic acid, cyclobutyl heptadecyl ester & - & 94.65 & - & 1618 \\
\hline 24.375 & $\begin{array}{l}\text { 1-Methyltridecyl } \\
\text { cyclobutanecarboxylate }\end{array}$ & - & - & 143.85 & 1664 \\
\hline \multirow[t]{2}{*}{36.708} & Hexadecanoic acid, ethyl ester & - & - & 593.25 & 2260 \\
\hline & Grand total & 37.50 & 94.65 & 1010.40 & \\
\hline 22.253 & 2-Hexynoic acid & 3.00 & 37.20 & 33.90 & 1575 \\
\hline \multirow[t]{2}{*}{29.844} & Nonahexacontanoic acid & - & 99.75 & - & 1910 \\
\hline & Grand total & 3.00 & 136.95 & 33.90 & \\
\hline 21.641 & Ethanedial, dioxime & - & - & 100.80 & 1551 \\
\hline 26.890 & 2,4-Dimethyl-benzenamine & 125.10 & - & - & 1773 \\
\hline 27.017 & 3-butenamide & - & - & 56.10 & 1779 \\
\hline 27.306 & (Z)-2-butenediamide & - & 30.00 & - & 1792 \\
\hline 27.929 & 1-octadecanamine & - & 13.20 & - & 1820 \\
\hline 7.336 & N-carboxal-4-carboxychloropi-peridine & 6.15 & 4.65 & 6.00 & 992 \\
\hline 13.381 & 2-Pentyl-furan & 72.30 & 932.10 & 263.10 & 1239 \\
\hline 18.469 & (Z)-aconitic anhydride & 3.30 & 3.30 & 9.15 & 1427 \\
\hline 19.276 & 2-methylpiperazine & 34.65 & - & - & 1458 \\
\hline 19.357 & 1-(aminoacetyl)-Piperazine & - & - & 66.00 & 1461 \\
\hline 19.876 & 3-Furan-2-yl-1-methyl-propyla-mine & - & 18.00 & - & 1481 \\
\hline 20.165 & 1-Fluoro-dodecane & 11.85 & - & 151.20 & 1492 \\
\hline 21.480 & 2-N-octylfuran & - & 39.45 & - & 1543 \\
\hline 22.068 & N-methyl-1,3-Propanediamine & - & - & 10.05 & 1568 \\
\hline 22.253 & 5-Methyl-2-furancarboxaldehyde & - & - & 48.75 & 1575 \\
\hline 24.122 & 4-Methylthiazole & - & 247.20 & - & 1653 \\
\hline 24.756 & Pentanoic acid, 2-methyl-, anhydride & - & 298.95 & - & 1680 \\
\hline 28.713 & 1-Sec-butyldiaziridine & - & - & 83.40 & 1857 \\
\hline \multirow[t]{2}{*}{32.358} & 1,54-Dibromotetrapentacontane & - & - & 71.85 & 2033 \\
\hline & & 253.35 & 1586.85 & 866.40 & \\
\hline
\end{tabular}

“-”: The corresponding substance was not detected by the instrument. "RT": Retention time. 
Table 2. Species and relative contents of volatile substances in fish meat under different processing methods.

\begin{tabular}{ccccc}
\hline & \multicolumn{2}{c}{ Unfermented group } & \multicolumn{2}{c}{ Fermented group } \\
\cline { 2 - 5 } & Type & Relative content & Type & Relative content \\
\hline Alcohols & 12 & $40.60 \%$ & 18 & $37.63 \%$ \\
Aldehydes & 14 & $38.70 \%$ & 16 & $32.46 \%$ \\
Ketones & 8 & $9.93 \%$ & 9 & $18.42 \%$ \\
Hydrocarbons & 9 & $4.19 \%$ & 4 & $6.27 \%$ \\
Esters & 1 & $0.34 \%$ & 5 & $2.76 \%$ \\
Acids & 2 & $0.50 \%$ & 1 & $0.09 \%$ \\
Heteroatoms/Heterocycles & 9 & $5.74 \%$ & 11 & $2.36 \%$
\end{tabular}

aroma of salted fish and make up for the shortage of pickled flavor of semi-dried fish.

According to Table 1 and Table 2, 55 and 64 of volatile compounds were detected in fresh fish, non-fermented fish and fermented fish, most of which were alcohols, aldehydes and ketones, accounting for $89.23 \%$ and $88.51 \%$ respectively. As a result, alcohols and carbonyl compounds were the main volatile components of grass carp fish flavor. The total contents of alcohols and aldehydes in semi-dried grass carp after fermentation were $9.21 \%$ lower than those in non-fermented fish. Moreover the contents of ketones, hydrocarbons and esters were significantly increased, indicating that the fermentation of Monascus had a significant effect on the flavor of the semi-dried grass carp.

\subsection{Identification of Key Aroma Substances}

Why did fresh fish, unfermented fish and fermented fish have similar flavor components while the overall flavor was significantly different? Some data showed that the flavor contribution of volatile flavor substances was determined by their concentration and flavor threshold. The flavor characteristics of fermented fish could not be accurately described by the content of flavor substances alone [21] [22] [23].

The volatile substance of which the concentration was highest in the fermentation group was the nonanal with $2767.5 \mathrm{ug} / \mathrm{kg}$, and the sensory threshold of it was $1 \mathrm{ug} / \mathrm{kg}$ [24], which contributed the most to the flavor of fermentation group. Thus, the nonanal was defined as the component with maximum contribution to odors. The sensory thresholds of some substances were not found in this paper. Most of them were hydrocarbons, esters and heteroatoms with high boiling point or high threshold, which had little effect on the overall flavor of fish. Volatile compounds of ROAV $>0.1$ were counted in Table 3. Some researches suggested that the components of ROAV $>1$ were key flavor compounds, those of $0.1<\mathrm{ROAV}<1$ were modified flavor compounds, and those of ROAV $<0.1$ were potential flavor compounds [9]. 
Table 3 showed that the main flavor substances (ROAV > 1) of Monascus fermented semi-dried grass carp were as follows: 1-octene-3-ol, phenylethanol, hexanal, heptanal, nonanal, (E)-2-octenal, 3-Methyl-1-butanal, benzaldehyde, (E)-2-nonenal, (E,E)-2,4-heptadienal, (E)-2-Decenal, phenylacetaldehyde, (E,E)-2.4decadienal, tetradecanal, 2,3-butanone, 2,3-octanedione, alpha-pinene, 2-pentane furan. The content of saturated straight-chain alcohols in alcohols was higher, which contributed little to the flavor of fermented fish meat because of their high sensory threshold. However, some unsaturated alcohols had low threshold, such

Table 3. Aroma characteristics, threshold and relative activity value of volatile components in semi-dried fish fermented by Monascus.

\begin{tabular}{|c|c|c|c|c|}
\hline & Compound name & $\begin{array}{l}\text { Sensory threshold } \\
\text { (ug/kg) [21] [23] } \\
{[24][25][26]}\end{array}$ & ROAV & $\begin{array}{l}\text { Fragrance Description } \\
{[21][23][27][28]}\end{array}$ \\
\hline \multirow{6}{*}{ Alcohols } & 3-Methyl-1-butanol & 300.00 & 0.26 & Nutty, herbaceous \\
\hline & Hexanol & 500.00 & 0.05 & Green, grassy, fatty \\
\hline & 1-Octen-3-ol & 1.00 & 66.03 & Mushroom, earthy \\
\hline & Octanol & 190.00 & 0.07 & Earthy, metallic \\
\hline & Nonanol & 50.00 & 0.14 & Chamomile, flowery, musty \\
\hline & Phenylethanol & 86.00 & 1.68 & Honey, rose, lilac, spicy \\
\hline \multirow{14}{*}{ Aldehydes } & Butanal & 5.26 & 0.23 & Special \\
\hline & Pentanal & 27.00 & 0.34 & Irritant \\
\hline & Hexanal & 4.50 & 18.18 & Green, fresh \\
\hline & Heptanal & 3.00 & 12.09 & Green \\
\hline & Nonanal & 1.00 & 100 & Green, citrus-like \\
\hline & (E)-2-octenal & 3.00 & 2.45 & Gramineous, fatty \\
\hline & 3-Methyl-1-butanal & 1.10 & 21.88 & Malt \\
\hline & Benzaldehyde & 3.00 & 1.41 & Bitter almonds, cherries nuts \\
\hline & (E)-2-nonenal & 0.08 & 28.46 & Fatty, tallow \\
\hline & (E, E) -2,4-heptadienal & 10.00 & 1.04 & Fatty, hay, fishy odor \\
\hline & (E)-2-decenal & 0.4 & 3.25 & Wax, fat and mushroom \\
\hline & Phenylacetaldehyde & 4.00 & 8.54 & Floral \\
\hline & (E,E)-2,4-decadienal & 0.2 & 21.14 & Fatty, waxy \\
\hline & Tetradecanal & 5.00 & 21.38 & Fishy smell \\
\hline \multirow{3}{*}{ Ketones } & 2,3-Butanedione & 5.00 & 6.40 & Fishy smell \\
\hline & 2,3-Octanedione & 2.52 & 19.56 & Creamy, caramel, butter scotch \\
\hline & 3-Hydroxy-2-butanone & 800.00 & 0.18 & Milky, fatty \\
\hline Hydrocarbons & Alpha-pinene & 6.00 & 10.84 & Turpentine \\
\hline Esters & Ethyl acetate & 5.00 & 0.54 & Fruity, buttery, orange \\
\hline Heterocycles & 2-Pentyfuran & 6.00 & 1.58 & Bean, grass \\
\hline
\end{tabular}


as 1-octene-3-alcohol and phenylethanol, which gave fermented fish meat mushroom and rose fragrance. Aldehydes, due to their low sensory threshold, accounted for the largest proportion of the main flavor substances in fermented fish meat, giving fish a variety of flavors. Ketones gave fermented fish fragrance, creamy fragrance and ester fragrance. Alpha-pinene and 2-pentylfuran gave the fermented fish oil and bean fragrance.

\section{Conclusion}

The volatile components of fresh fish, semi-dried fish and semi-dried fish fermented by Monascus were analyzed by SDE combined with GC-MS, and 43, 56 and 64 of volatile substances were detected respectively. The results showed that alcohols, aldehydes and ketones were the main components of the flavor of grass crap. The semi-dried fish fermented by Monascus could significantly affect the flavor of semi-dried grass carp. Furthermore, the processing could not only effectively improve the fishy smell of fresh fish, but also enhance the aroma of salted fish, and make up for the shortcomings of the pickled flavor of semi-dried fish. 18 of the main flavor components of semi-dried fish fermented by Monascus were identified by relative odor activity value (ROAV). They were as follows: 1-octene-3-ol, phenylethanol, hexanal, heptanal, nonanal, (E)-2-octenal, 3-Methyl1-butanal, benzaldehyde, (E)-2-nonenal, (E,E)-2,4-heptadienal, (E)-2-decenal, phenylacetaldehyde, (E,E)-2.4-decadienal, tetradecanoaldehyde, 2,3-butanone, 2,3-octanedione, a-pinene, 2-pentane furan. The main aroma characteristics were mushroom, rose, gramineous, citrus taste, Vegetable-flavored, malt, bitter almond-flavored, cherry and nut-flavored, the fragrance of a flower, cream-flavored, fruit-flavored and wine-flavored.

\section{References}

[1] Zhang, L., Li, X., Lu, W., Shen, H.-X. and Luo, Y.-K. (2011) Quality Predictive Models of Gress Carp (Ctenopharyngodon idella) at Different Temperatures during Storage. Food Control, 22, 1197-1202. https://doi.org/10.1016/j.foodcont.2011.01.017

[2] Kang, C.-C., Shi, W.-Z., Fang, L. and Wang, X.-C. (2018) Effects of Different Freezing Methods on the Volatile Components of Grass Carp Meat. Food Science, 39, 229-235.

[3] Jin, J., Wu, L.-F., Wang, Q.-D., Wu, J.-Z. and Zeng, S.-D. (2011) Effects of Fermentation by Lactic Acid Bacteria on the Volatile Components of Damp-Dry Tilapia. Journal of Jinan University (Natural Science \& Medicine Edition), 32, 473-479.

[4] You, G. and Niu, G.-G. (2016) Study on the Volatile Flavor Compounds of Nemipterus virgatus Inoculated with Complex Lactic Acid Bacteria. Food and Fermentation Industries, 42, 167-173.

[5] Wu, H.-Y., Yang, L., Li, S.-D., Wang, G. and Yang, X.-H. (2010) Effects of Mixed Starter Cultures on the Quality of Fermented Cured Fish. Guangzhou Chemical Industry, 38, 73-77.

[6] Udomsil, N., Rodtong, S., Tanasupawat, S. and Yongsawatdigul, J. (2015) Improvement of Fish Sauce Quality by Strain. Journal of Food Science, 80, M2015-M2022. 
https://doi.org/10.1111/1750-3841.12986

[7] Zhang, C., Song, Z.-L., Li, F.-E. and Wu, J.-Z. (2017) Influence of Monascus Fermentation on Storage Characteristics of Semidry Salted Tilapia. Journal of Aquatic Food Product Technology, 10, 1122-1133. https://doi.org/10.1080/10498850.2014.914116

[8] Moradi, P., Ford-Lloyd, B. and Pritchard, J. (2017) Metabolomic Approach Reveals the Biochemical Mechanisms Underlying Drought Stress Tolerance in Thyme. Analytical Biochemistry, 527, 49-62. https://doi.org/10.1016/j.ab.2017.02.006

[9] Niu, D.-Y., Zhou, G.-H. and Xu, X.-L. (2008) "ROAV” Method: A New Method for Determining Key Odor Compounds of Rugao Ham. Food Science, 29, 370-374.

[10] Frauendorfer, F. and Schieberle, P. (2006) Identification of the Key Aroma Compounds in Cocoa Powder Based on Molecular Sensory Correlations. Journal of Agricultural and Food Chemistry, 54, 5521-5529. https://doi.org/10.1021/jf060728k

[11] Maurizio, B., Gianluca, G., Gandini, G., Caccialanza, G., Finzi, P.V., Vidaric, G., et al. (2007) Determination of the Threshold Odor Concentration of Main Odorants in Essential Oils Using Gas Chromatography-Olfactometry Incremental Dilution Technique. Journal of Chromatography A, 1150, 131-135. https://doi.org/10.1016/j.chroma.2007.02.031

[12] Wu, J.-Z., Wang, Q.-Q., Liao, S., Wu, K. and Zhang, M.-M. (2019) Causes Analysis of Deodorization of Saury Soup by Angel Yeast Fermentation. Food and Fermentation Industries, 45, 213-220.

[13] Zhou, Y.-Q. and Wang, Z.-J. (2006) Extraction and Analysis on Fishy Odor-Causing Compounds in the Different Part of Carp. Chinese Journal of Analytical Chemistry, 34, 165-167.

[14] Wang, X., Huang, J., Hou, Y.-D. and Wang, Q.-J. (2012) Analysis of Volatile Components in Yellowfin Tuna by Electronic Nose and GC-MS. Food Science, 33, 268-272.

[15] Qian, P., Ma, X.-T., Xu, G., Xue, J., Jin, R.-Y. and Dai, Z.-Y. (2016) Study on Volatile Components and Deodorization of Silver Carp. Journal of Chinese Institute of Food Science and Technology, 16, 169-173.

[16] Huang, Z.-B., Ming, T.-H. and Dong, L.-S. (2019) Studies on the Deodorization during Fermentation of Tuna's Milt by Lactobacillus plantarum. Journal of Chinese Institute of Food Science and Technology, 19, 147-154.

[17] Wu, H.-Y., Xie, W.-C., Yang, X.-H., Yang, L., Li, S.-L. and Zhang, C.-H. (2009) SPME-GC-MS Analysis of Volatile Components in Cured Golden Thread (Nemipterus virgatus) Meat. Food Science, 30, 278-281.

[18] Li, L.-H., Ding, L.-L., Wu, Y.-Y., Yang, X.-Q., Deng, J.-Z. and Liu, F.-J. (2012) Analysis of the Volatile Flavor Compounds in Salted-Dried Fish. Journal of Fisheries of China, 36, 979-988. https://doi.org/10.3724/SP.J.1231.2012.27682

[19] Wu, Y.-Y., Li, L.-H., Yang, X.-Q., Niu, F.-J., Diao, S.-Q. and Deng, J.-C. (2011) Changes of Volatile Flavor Compounds during Salted Hairtail (Trichiurus haumela) Processing. Food Science, 32, 208-212.

[20] Wang, Y., Wang, R.-D., Xue, Y., Zhao, Y.-N. and Xue, C.-H. (2018) Analysis of Volatile Flavor Compounds Changes during Traditional Processing of Salted Spanish Mackerel. Modern Food Science and Technology, 34, 268-276.

[21] Cai, R.-K., Wu, J.-J., Zhu, J.-L., Qian, P. and Dai Z.-Y. (2017) Analysis of Volatile Compounds and Odor-Active Compounds in Fermented Large Yellow Croaker. Journal of Chinese Institute of Food Science and Technology, 17, 264-273. 
[22] Gao, J.-C., Ye, P. and Huan, Y.-J. (2019) Effects of Single Bacteria and Compounded Bacteria Fermentation on Volatile Compounds of Pork Jerky. Food and Fermentation Industries, 1, 128-136.

[23] Lu, C.-X., Wong, L,-P., Wang, H.-H., Yang, R.-H., Wang, X.-F. and Dai, Z.-Y. (2010) Investigation on the Key Odor Compounds of Three Cage-Farming Fishes. Food and Fermentation Industries, 36, 163-169.

[24] Pino, J.A. and Mesa, J. (2006) Contribution of Volatile Compounds to Mango (Mangifera indica L.) Aroma. Flavour and Fragrance Journal, 21, 207-213. https://doi.org/10.1002/ffj.1703

[25] Zhu, L.-L., Yang, F., Gao, P., Jiang, Q.-X., Xu, Y.-S. and Yu, P.-P. (2018) Effect of Fermentation Conditions on Flavor of Yeast-Fermented and Wine-Aroma Sturgeon (Acipenser dabryanus). Food and Fermentation Industries, 44, 110-117.

[26] Selli, S. and Gayhan, G.C. (2009) Analysis of Volatile Compounds of Wild Gilthead Sea Bream (Sparus aurata) by Simultaneous Distillation-Extraction (SDE) and GC-MS. Microchemical Journal, 93, 232-235.

https://doi.org/10.1016/j.microc.2009.07.010

[27] Anupam, G., Kazufumi, O., Akira, O. and Toshiaki, O. (2010) Olfactometric Characterization of Aroma Active Compounds in Fermented Fish Paste in Comparison with Fish Sauce, Fermented Soy Paste and Sauce Products. Food Research International, 43, 1027-1040. https://doi.org/10.1016/j.foodres.2010.01.012

[28] Morales, M.T., Rios, J.J. and Aparicio, R. (1997) Changes in the Volatile Composition of Virgin Olive Oil during Oxidation: Flavors and Off-Flavors. Journal of Agricultural and Food Chemistry, 45, 2666-2673. https://doi.org/10.1021/jf960585+ 